Goran Majstrović

Energy Institute Hrvoje Požar (EIHP)

Croatia

\section{Davor Bajs}

Energy Institute Hrvoje Požar (EIHP)

Croatia

Lucija Krstanović

Energy Institute Hrvoje Požar (EIHP)

Croatia

\section{Damjan Međimorec}

Croatian Transmission System Operator (HOPS) Croatia

Danko Blažević

Croatian Transmission System Operator (HOPS) Croatia

\section{Saša Cazin}

Croatian Transmission System Operator (HOPS)

Croatia

\section{Martina Mikulić}

Croatian Power Company (HEP)

Croatia
Multicriterial analyses and selection of the best option for revitalization and development of the southern part of Croatian 400 $\mathrm{kV}$ network and connection to the power system of Bosnia and Herzegovina

\title{
SUMMARY
}

The southern wing of the Croatian transmission network was constructed for $220 \mathrm{kV}$ in the early 1960 's, with additional $400 \mathrm{kV}$ reinforcement at the end of 1970's. Its route of more than $200 \mathrm{~km}$ is quite demanding due to extreme climate, environmental specifics and related costs. However, operational experience during more than 50 years has been quite positive. Nowadays, at the end of its lifetime it is again extremely important to analyze and select the best option for network revitalization and development to serve the network users for the next 50 years, but in very different conditions of technological development, more restrictive environmental requirements, electricity market conditions and large scale RES integration. Moreover, special attention should be given to the potential opportunity and need to use this revitalization also for new interconnection to the power system of Bosnia and Herzegovina (BiH).

Altogether with its length of more than $380 \mathrm{~km}$ this is one of the largest transmission projects in South East Europe in the last few decades. This paper presents the main findings of the multicriterial and comprehensive study covering technical, economic, financial, geographical, environmental, social and legal assessment, identifying locations of new $400 \mathrm{kV}$ transmission system nodes, internal and interconnection $400 \mathrm{kV}$ lines routes, together with the potential upgrade/replacement of the existing $220 \mathrm{kV}$ circuits.

Network analyses have been prepared on more than 180 different scenarios using PSS/E software, while market analyses were completed for 21 selected scenarios using PLEXOS software. Scenarios were based on the following criteria/uncertainties related to the power systems of Croatia and $\mathrm{BiH}$ :

1. analyzed time-horizons (2023 and 2028)

2. demand growth (referent, low, high)

3. analyzed operation conditions (winter/summer peak/off peak load)

4. generation scenarios (high, low, new RES, $\mathrm{CO}_{2}$ prices)

5. hydrological and climate conditions (average, extreme hydrology and wind speed)

6. power balance (import, export)

7. power transits 
Five main options have been initially selected as topology candidates for problem resolving. Detailed methodology and criteria for the selection of optimal option [revitalization and development scenario and topology] were developed and approved by all involved stakeholders. For selected option, based on comprehensive analyses and approved methodology, for further detailed analyses [ system reliability, technical design, investment, economics /CBA/ and environmental analyses) have been prepared, including assessment of its impact on transmission tariffs of each country.

Sensitivity analyses to the most uncertain variables (investment costs and $\mathrm{CO}_{2}$ prices] were also performed.

The environmental and social assessment was very demanding due to the complex governance structure and three legal frameworks to be respected [two countries, along with two entities in $\mathrm{BiH}$ ]. The Project impact was evaluated with respect to: air quality, water quality, waste management, noise, biological diversity, electromagnetic field, social measures and protected areas.

This paper presents above mentioned analyses, findings and recommendations, as the most comprehensive analytical approach to the transmission line development that's ever been applied in this region.

\section{KEYWORDS}

Multicriterial analyses, 400 kV network development, Croatia, Bosnia and Herzegovina [BiH]

\section{PROJECT BACKGROUND}

The southern $400 \mathrm{kV}$ and $220 \mathrm{kV}$ wing of the Croatian transmission network was constructed in 1960's and 1970's. It is crucial infrastructure for transmission of large-scale hydro generation located in the south of Croatia and $\mathrm{BiH}$ [>2000 MW] to larger consumption areas on the north and further export to the west [Slovenia, Italy]. Very positive operational experience with this part of the network in the last 50 years proves that the network planning and project preparation at that time has been done successfully using adequate optimization techniques. However, as lifetime of that infrastructure is close to its end, now it is again extremely important to analyze and select the best option for network revitalization and development to serve the network users for the next 50 years, having in mind that operational conditions are very different from technological, spatial, environmental and economic perspective, including much more uncertainties than 50 years ago. The need for upgrading of the existing transmission network in this area is further boosted in the last few years with huge interest in RES integration (>3000 MW] due to high wind and solar potential.

Therefore, the feasibility study [1] has been launched for strengthening $400 \mathrm{kV}$ transmission line corridor Konjsko - Lika - Melina in Croatia, and new interconnection line to Banja Luka in BiH taking into account existing and expected power system conditions in Croatia, $\mathrm{BiH}$ and wider region. The main aim of this analysis was to prepare a full feasibility study for the project comprising of two transmission subprojects:

1. internal line in Croatia and

2. interconnection line between Croatia and $\mathrm{BiH}$

as shown in the following Figure.

The feasibility study [1] resulted with 8 reports (deliverables) on more than 1200 pages and 3 workshops and trainings.
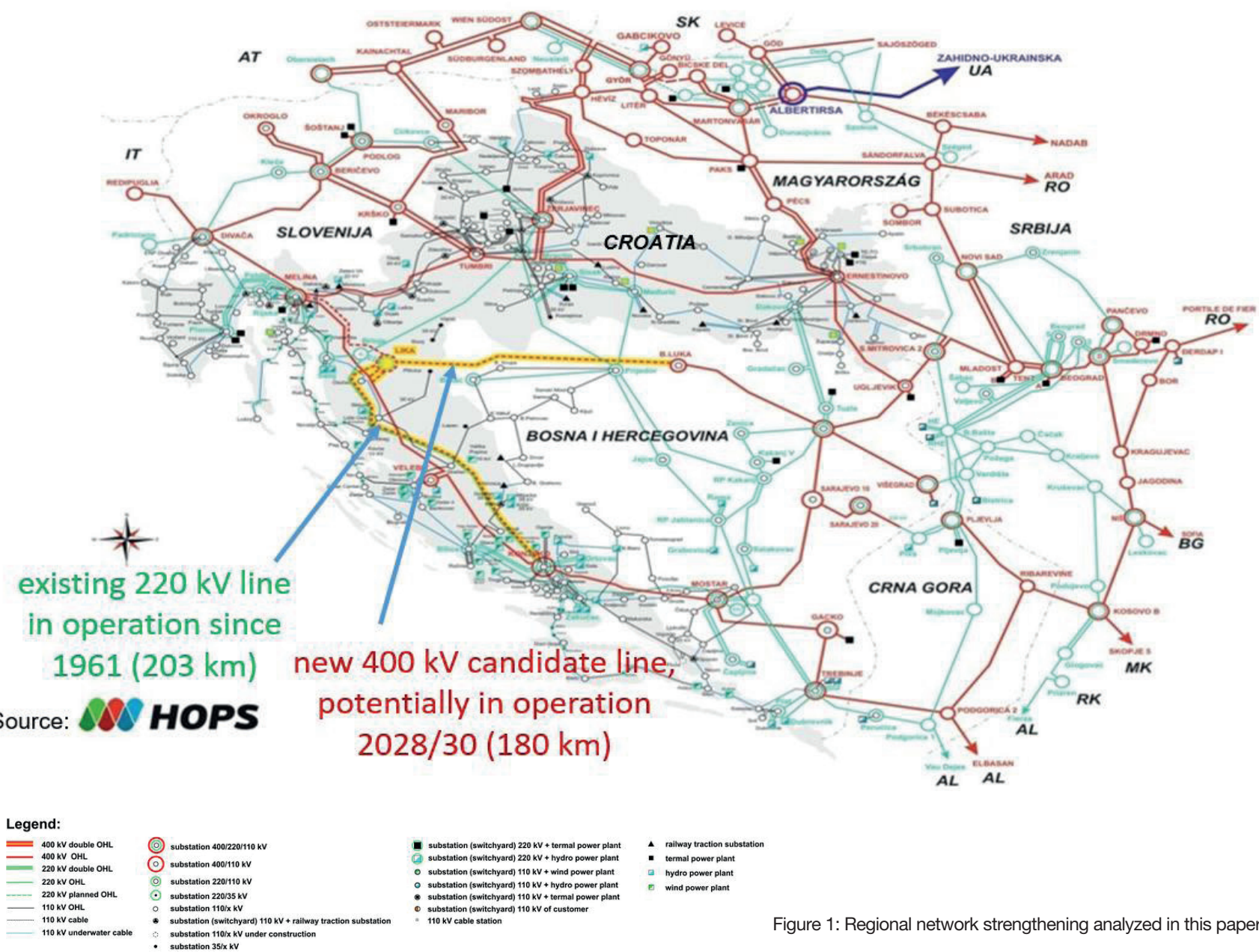

Figure 1: Regional network strengthening analyzed in this paper 


\section{PROJECT PROMOTERS AND THE SCOPE}

Thirteen institutions/companies (promoters and stakeholders) from both countries have participated in this study analysis. Three promoters were divided in two groups:

1. the Client: Croatian Transmission System Operator - HOPS and

2. the Partners:

- $\quad \mathrm{BiH}$ Transmission Company - Elektroprijenos $\mathrm{BiH}$ and

- $\quad \mathrm{BiH}$ Independent System Operator - NOS BiH

Knowing of the project key importance in the future regional electricity system and market development, ten project stakeholders also had important role: EBRD, state environmental agencies, state IPA coordinators, line ministries and regulatory agencies.

In addition to above mentioned 13 institutions/companies, the Consortium of 3 consulting companies also actively participated, preparing all the calculations and the reports. Accordingly, in total 16 institutions/companies participated in this comprehensive activity and project governance, as shown in the following figure. The Client and Partners appointed 22 multidisciplinary experts to support the project, while the Consultants engaged 26 experts. The whole task was carried out by the project team of 48 ex perts in total. The project lasted for 12 months (March 2018 - March 2019) with 8 meetings in Croatia and $\mathrm{BiH}$.
The scope of the project was:

1. to analyze all potential scenarios of revitalization and strengthening of transmission line corridor Konjsko - Lika - Melina in Croatia

2. to evaluate the need for and assess the feasibility of new interconnection line with $\mathrm{BiH}$

3. to harmonize network development between two neighboring systems, taking into account existing and expected power system conditions in Croatia, $\mathrm{BiH}$ and the region

4. to prepare a full feasibility study for the project comprising of two transmission subprojects (internal line in Croatia and interconnection line between Croatia and $\mathrm{BiH})$, using detailed:

- Technical,

- Economical,

- Spatial

- Environmental and

- Social assessment.

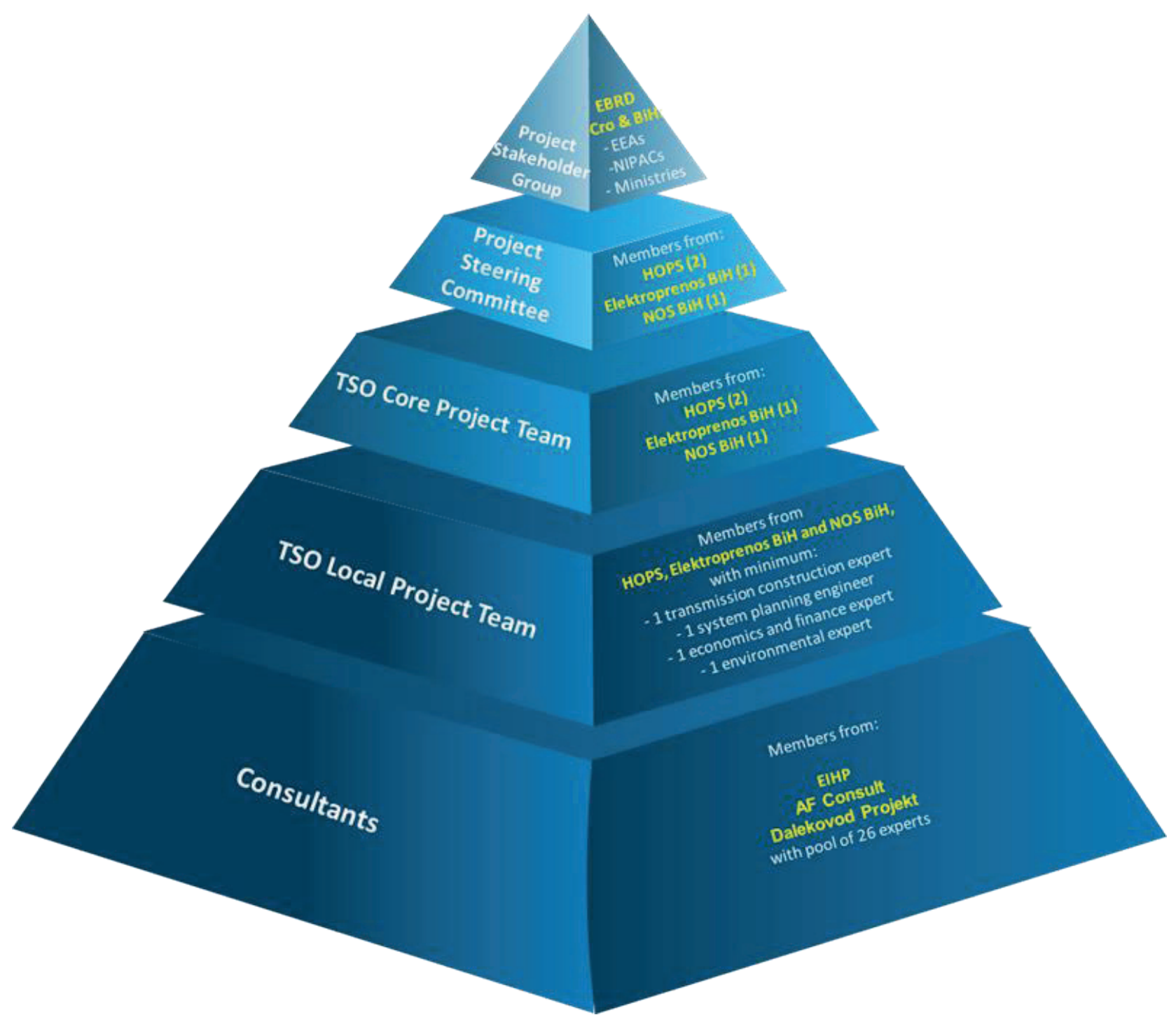

Figure 2: Feasibility study project governance 


\section{MAIN ELEMENTS AND APPRAISAL METHODOLOGY}

Five main options have been initially selected as topology candidates related to Croatian internal network for adequate problem resolving. These options were based on different voltage level, line routes and number of circuits in Croatia as follows:

1. Existing $\mathrm{OHL} 220 \mathrm{kV}$ Brinje - Konjsko with new conductors of the same type (ACSR 360)

2. Existing OHL 220 kV Brinje - Konjsko with new conductors of different type (HTLS conductors)

3. New $1 \times 400 \mathrm{kV}$ using existing $220 \mathrm{kV}$ line route and new SS 400/x kV Lika including in/out of Melina - Velebit $400 \mathrm{kV}$

4. New $2 \times 400 \mathrm{kV}$ using existing $220 \mathrm{kV}$ line route and new SS 400/x kV Lika including in/out of Melina - Velebit $400 \mathrm{kV}$

5. New $1 \times 400 \mathrm{kV}$ using new line route to new SS 400/x kV Lika and keeping existing OHL 220 kV Brinje - Konjsko All input data, scenarios and methodologies were approved by the Core Project Team and the Project Steering Committee. The methodology for selection of one optimal scenario was developed and agreed among all stakeholders and it was based on multicriterial approach. This approach relies on five different criteria (factors): electrical, administrative, market, cost and environmental/social (Table 1).

Previously listed topological scenarios have been evaluated through these factors, where each factor has its own weighting factor. Electrical factor was taken as the most important. It was based on the power system analyses in more than 180 different scenarios using PSS/E software package and complete and verified power system model of the whole region of South East Europe taking into account official 10-year network development plans of all regional power systems and the ENTSO-e.

Seven electrical factors have been used in the evaluation matrix:

1. number of scenarios in which a violation of the $\mathrm{N}$ criterion is identified

2. number of critical branches identified with respect to $\mathrm{N}$ network availability

3. number of scenarios in which a violation of the $\mathrm{N}-1$ criterion is identified

4. number of critical branches identified with respect to $\mathrm{N}-1$ network availability

5. number of scenarios in which a violation of the $\mathrm{N}-1-1$ criterion is identified with respect to $400 \mathrm{kV}$ and $220 \mathrm{kV}$ network

6. number of critical branches identified with respect to $\mathrm{N}-1-1$ network availability with respect to $400 \mathrm{kV}$ and $220 \mathrm{kV}$ networks

7. average power losses for all scenarios

Table 1: Resulting table with evaluation factors

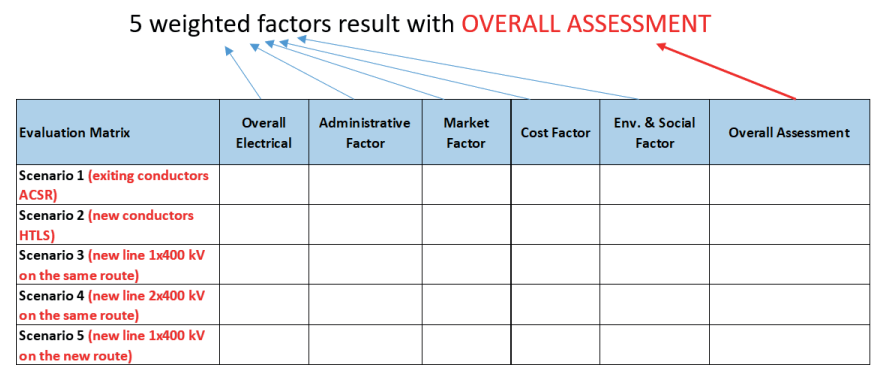

Large number of scenarios (>180) is the consequence of different uncertainties related to the power systems of Croatia and $\mathrm{BiH}$ :

1. analyzed time-horizons (2023 and 2028)

2. demand growth (referent, low, high)

3. analyzed operation conditions (winter/summer peak/off peak load)

4. generation scenarios (high, low, impact of new RES, $\mathrm{CO}_{2}$ prices)

5. hydrological and climate conditions (average, extreme hydrology and wind speed)

6. power balance (import, export)

7. power transits

Every single topological scenario resulted with its overall electrical factor That value described scenario importance from the electrical perspective.

Market factor used in the evaluation matrix was based on 15 selected mar ket scenarios. Each scenario resulted with country power balance, electricity price, total generation cost and net import cost. Similar as in network calculations, whole South East Europe was modelled using PLEXOS software tool covering 12 regional countries and 4 perimeter countries. The model included 550 generators, 24 interconnection lines and 2 HVDC links, along with complete 110, 220 and 400 kV network in Croatia and $\mathrm{BiH}$

Market scenarios differ in time horizon, circuit type (HTLS or ACSR conductors), $\mathrm{CO}_{2}$ price variations, with or w/o link to $\mathrm{BiH}$. Special emphasis in market analysis was given to EUCO 2030 scenario prepared by the European Commission and presented in the ENTSO-E TYNDP 2018. It provided additional overview of expected European energy future up to 2030 and beyond.

Administrative factor used in the evaluation matrix assumed complexity of formal project development procedures for each scenario. This factor can have two values: "yes" (it is feasible in given timeframe) or "no" (not feasible in given timeframe). Based on the construction practice and formal procedures and deadlines in Croatia it is not feasible to prepare and build new $400 \mathrm{kV}$ line using new $200 \mathrm{~km}$ long route in just 5 years. Therefore, these options were evaluated with negative administrative factor.

Cost factor used in the evaluation matrix reflected estimated construction cost for given topological scenario, while environmental and social factor used in the evaluation compares environmental and social risks.

The best topological scenario for each evaluation factor is awarded with 10 points, while other scenarios are normalized to that value. Weighting factors for each factor were based on its importance and have been approved by the project team, as given below in the table. Linear combination of evaluation factors and its weighting factors results with overall assessment value for each topological scenario.

Large number of scenarios covered a majority of all expected power system regimes and uncertainties in both countries, including additional sensitivity analysis in economic assessment. Accordingly, the study results can be taken as proven on the adequate set of input data, scenarios and assumptions, as well as adopted and harmonized between two neighboring system operators.

\section{SCENARIO COMPARISON ANALYSES}

Based on the above-mentioned criteria and methodology scenario evaluation matrix for 2023 is given in the following table. The largest overall assessment value in 2023 is given to scenario 2 - existing OHL 220 kV Brinje - Konjsko with new HTLS conductors. Scenarios 3, 4 and 5 are estimated as not feasible till 2023. So, for short-term time frame scenario 2 is evaluated as the best option, having the best overall electrical and environmental \& social factor (using existing route, so with no additional environmenta impact), very good cost factor, but quite low market factor.

Table 2: Scenario evaluation matrix for 2023

\begin{tabular}{|c|c|c|c|c|c|c|}
\hline Weighting factors & 40 & & 20 & 20 & 20 & \\
\hline Evaluation Matrix & $\begin{array}{l}\text { Overall } \\
\text { Electrical }\end{array}$ & $\begin{array}{l}\text { Administrative } \\
\text { Factor }\end{array}$ & Market Factor & Cost Factor & \begin{tabular}{|c|} 
Env. \& Social \\
Factor
\end{tabular} & Overall Assessment \\
\hline $\begin{array}{l}\text { Scenario 1 (exiting } \\
\text { conductors ACSR) }\end{array}$ & 8,32 & YES & 0,00 & 10,00 & 9,00 & 7,13 \\
\hline $\begin{array}{l}\text { Scenario } 2 \text { (new conductors } \\
\text { HTLS) }\end{array}$ & 9,67 & YES & 0,80 & 9,07 & 10,00 & 7,84 \\
\hline $\begin{array}{l}\text { Scenario } 3 \text { (new line } 1 \times 400 \\
\mathrm{kV} \text { on the same route) }\end{array}$ & 0,56 & No & 8,53 & 3,31 & 6,63 & $\begin{array}{c}3,92 \\
\text { (not feasible until 2023) } \\
\end{array}$ \\
\hline $\begin{array}{l}\text { Scenario } 4 \text { (new line } 2 \times 400 \\
\text { kV on the same route) }\end{array}$ & 0,00 & No & 10,00 & 0,00 & 5,06 & $\begin{array}{c}3,01 \\
\text { (not feasible until 2023) }\end{array}$ \\
\hline $\begin{array}{l}\text { scenario } 5 \text { (new line } 1 \times 400 \\
k V \text { on the new route) }\end{array}$ & 10,00 & No & 3,86 & 4,51 & 0,00 & $\begin{array}{c}5,67 \\
\text { (not feasible until 2023) }\end{array}$ \\
\hline
\end{tabular}

The same approach was used for 2028 timeframe in two sub-scenarios: without and with new interconnection to $\mathrm{BiH}$, as given in the following two tables. The largest overall assessment value for 2028 without OHL 400 kV Lika - Banja Luka is given to scenario 5 - new $1 \times 400 \mathrm{kV}$ using new line route to new SS 400/x kV Lika and keeping revitalized OHL $220 \mathrm{kV}$ Brinje - Konjsko (including in/out SS 220/x kV Krš Pađene). All scenarios are feasible till 2028, having positive administrative factor. So, for longerterm time frame scenario 5 is evaluated as the best option, having the best overall electrical factor, acceptable cost factor, but lower market factor and the lowest environmental \& social factor (using new route, so with the 
largest environmental impact).

Table 3: Scenario evaluation matrix for 2028 without new interconnection Croatia - $\mathrm{BiH}$

\begin{tabular}{|c|c|c|c|c|c|c|}
\hline Weighting factors & 40 & & 20 & 20 & 20 & \\
\hline Evaluation Matrix & $\begin{array}{l}\text { Overall } \\
\text { Electrical }\end{array}$ & $\begin{array}{l}\text { Administrative } \\
\text { Factor }\end{array}$ & Market Factor & Cost Factor & $\begin{array}{c}\text { Env. \& Social } \\
\text { Factor }\end{array}$ & Overall Assessment \\
\hline \begin{tabular}{|l|} 
Scenario 1 (exiting \\
conductors ACSR)
\end{tabular} & - & - & - & - & - & - \\
\hline $\begin{array}{l}\text { Scenario } 2 \text { (new conductors } \\
\text { HTLS) }\end{array}$ & 0,00 & YES & 0,00 & 10,00 & 10,00 & 4,00 \\
\hline $\begin{array}{l}\text { Scenario } 3 \text { (new line } 1 \times 400 \\
\text { kV on the same route) }\end{array}$ & 3,23 & YES & 8,25 & 3,37 & 6,63 & 4,94 \\
\hline \begin{tabular}{|l} 
Scenario 4 (new line $2 \times 400$ \\
$k V$ on the same route)
\end{tabular} & 3,10 & YES & 10,00 & 0,00 & 5,06 & 4,25 \\
\hline $\begin{array}{l}\text { Scenario } 5 \text { (new line } 1 \times 400 \\
k V \text { on the new route) }\end{array}$ & 10,00 & YES & 5,89 & 4,59 & 0,00 & 6,10 \\
\hline
\end{tabular}

The largest overall assessment value for 2028 with OHL 400 kV Lika Banja Luka is given again to scenario 5 - new $1 \times 400 \mathrm{kV}$ using new line route to new SS 400/x kV Lika and keeping revitalized OHL 220 kV Brinje - Konjsko (including in/out SS 220/x kV Krš Pađene). This scenario has again the best overall electrical factor, good cost and market factor and the lowest environmental \& social factor.

Table 3: Scenario evaluation matrix for 2028 with new interconnection Croatia - $\mathrm{BiH}$

\begin{tabular}{|c|c|c|c|c|c|c|}
\hline Weighting factors & 40 & - & 20 & 20 & 20 & \\
\hline Evaluation Matrix & $\begin{array}{l}\text { Overall } \\
\text { Electrical }\end{array}$ & $\begin{array}{l}\text { Administrative } \\
\text { Factor }\end{array}$ & Market Factor & Cost Factor & $\begin{array}{l}\text { Env. \& Social } \\
\text { Factor }\end{array}$ & Overall Assessment \\
\hline $\begin{array}{l}\text { Scenario 1 (exiting } \\
\text { conductors ACSR) }\end{array}$ & & - & - & - & - & - \\
\hline $\begin{array}{l}\text { Scenario } 2 \text { (new conductors } \\
\text { HTLS) }\end{array}$ & 3,61 & YES & 0,00 & 10,00 & 10,00 & 5,44 \\
\hline $\begin{array}{l}\text { Scenario } 3 \text { (new line } 1 \times 400 \\
\text { kV on the same route) }\end{array}$ & 2,54 & YES & 4,89 & 3,37 & 6,63 & 3,99 \\
\hline \begin{tabular}{|l|} 
Scenario 4 (new line $2 \times 400$ \\
$\mathrm{kV}$ on the same route)
\end{tabular} & 0,00 & YES & 10,00 & 0,00 & 5,06 & 3,01 \\
\hline \begin{tabular}{|l|} 
Scenario 5 (new line $1 \times 400$ \\
$\mathrm{kV}$ on the new route)
\end{tabular} & 10,00 & YES & 5,66 & 4,59 & 0,00 & 6,05 \\
\hline
\end{tabular}

According to adopted methodology and criteria suggested revitalization strategy for the timeframe of 2023 is replacement of the existing conductors at the OHL $220 \mathrm{kV}$ Konjsko - Brinje with the new HTLS conductors. For 2028, the construction of new 400 kV line(s) Konjsko - Lika - Melina was suggested as the optimal scenario, no matter with or without new 400 $\mathrm{kV}$ interconnection Croatia - $\mathrm{BiH}$

For selected optimal scenario further detailed technical design, economics and environmental analyses have been prepared. Clearly, the main driver for selected network reinforcements in 2023 and 2028 was planned new RES generation development, including additional $841 \mathrm{MW}$ (low generation development scenario) to $2924 \mathrm{MW}$ (high generation development scenario) in Croatia till 2028, as well as 2509 MW (referent generation development scenario) to $2962 \mathrm{MW}$ (high generation development scenario) in $\mathrm{BiH}$.

New interconnection line 400 kV Lika (Croatia) - Banja Luka (BiH) should be commissioned if market conditions are going to be favorable for this line (for example large export from $\mathrm{BiH}$ or import to $\mathrm{BiH}$ due to real market conditions which will be strongly determined by $\mathrm{CO}_{2}$ emission price in the future). of losses, security of supply, reactive power compensation and voltage control),

4. technical design (line routes, substation locations, expected climate conditions, towers, foundations, conductors, earthwires, insultation, grounding and supporting equipment),

5. environmental impact assessment (legal and institutional overview, gap analysis, environmental scoping, impact assessment in Croatia and two entities in $\mathrm{BiH}$ ),

6. impact on transmission tariffs in both countries.

Due to limited available space only the most important outcomes are given in the concluding remarks of this paper.

\section{CONCLUSIONS}

CBA was performed for selected optimal scenario in 2028 (scenario 5) primarily on the principles established in the "2nd ENTSO-E Guideline for Cost-Benefit Analysis of Grid Development Projects" (Guidelines) [2]. Results of the cost-benefit analysis have shown that the benefits of the project to the society greatly outweigh the costs in the base case scenario. All calculated economic indicators have resulted in positive values, including ENPV and ERR. In the additional EUCO 2030 scenario, the project variant of OHL Lika-Banja Luka has resulted in negative profitability, which is a direct result of a much smaller socio-economic welfare benefit calculated in the market analysis.

Sensitivity analysis to the most uncertain variables was performed, i.e. to the change in investment costs and $\mathrm{CO}_{2}$ prices. Investment costs were varied by $10 \%$ and $20 \%$, while $\mathrm{CO}_{2}$ prices were varied in the market analysis and the resulting SEW was taken into consideration for calculating new economic indicators with these results. Sensitivity analysis performed on investment costs has also shown positive results for the 2028 scenario, both with up to $20 \%$ decrease and $20 \%$ increase in investment costs. However, not even a $20 \%$ decrease of investment resulted positive for OHL 400 kV Lika-Banja Luka in the EUCO 2030 scenario. Sensitivity analysis performed on $\mathrm{CO}_{2}$ prices has shown that an increase in $\mathrm{CO}_{2}$ prices would have positive impact at the results in all project options.

Technical design resulted with detailed assessment of the line route for OHL 400 kV Konjsko - Lika (203 km) and OHL 400 kV Lika - Banja Luka (53 km in Croatia and $127 \mathrm{~km}$ in $\mathrm{BiH})$, altogether $381 \mathrm{~km}$. Technical design for the existing and new substations was also prepared.

Environmental and social assessment was very demanding due to complex governance structure and three legal frameworks to be respected. The Project impact was evaluated in: 1) pre-construction and construction phase, 2) operational phase and 3) decommissioning phase with respect to: air quality, water quality, waste management, noise and vibration, biological diversity, electromagnetic field, social measures and protected areas. Final results proved that this project can be realized with minimal environmental impact avoiding protected areas and fulfilling all legal requirements. Relevant documents have been prepared for further formal steps in issuing environmental consents in both countries.

\section{SELECTED OPTIMAL SCENARIO ANALYSIS}

For selected optimal scenario additional detailed analyses have been taken, including:

1. network analyses (load flow and (n-1) security analyses, short-circuit calculations, transmission losses evaluation (annual electricity losses in transmission network of Croatia and $\mathrm{BiH}$, TTC/NTC calculations for Croatia/BiH border in both directions, voltage profile analyses, reliability assessment, transient stability analyses),

2. market analyses (overview of countries electricity balance in the region (production, consumption and exchanges), electricity prices for each country, total generation cost for each country, amount and cost of $\mathrm{CO}_{2}$ emissions for each country, cross-border power exchanges for each interconnection in the region),

3. cost-benefit assessment - CBA (socio-economic welfare (SEW), cost

BIBLIOGRAPHY

[1] Feasibility study for strengthening of main Croatian transmission North-South axis enabling new interconnection develop- ment, ElHP, Dalekovod Projekt, AF Consult, 2019

[2] $2^{\text {nd }}$ ENTSO-E Guideline for Cost-
Benefit Analysis of Grid Development Projects, 2018

[3] Methodology for grid connec tion fee determination related to new and existing network users in Croatia, HERA, 2018 